\title{
Determinación y cuantificación de subpoblaciones de linfocitos T y células natural killer en sangre periférica de individuos sanos por citometría de flujo
}

\author{
Israel Parra-Ortega ${ }^{1}$, Karen S. Salceda-Rangel1, Noemi Nájera-Martínez¹, Briceida López-Martínez¹, \\ Vianney Ortiz-Navarrete ${ }^{2}$ e Irlanda Olvera-Gómez ${ }^{3,4 *}$ \\ ${ }^{1}$ Laboratorio Clínico, Hospital Infantil de México Federico Gómez; ${ }^{2 B i o m e d i c i n a ~ M o l e c u l a r, ~ C e n t r o ~ d e ~ I n v e s t i g a c i o ́ n ~ y ~ d e ~ E s t u d i o s ~ A v a n z a d o s ~ d e l ~}$ \\ Instituto Politécnico Nacional (CINVESTAV); ${ }^{3}$ Universidad Anáhuac México Norte; ${ }^{4}$ Hospitales Federales de Referencia, Secretaría de Salud (SSA); \\ Hospital Nacional Homeopático, Unidad 160. Ciudad de México, México
}

\begin{abstract}
Resumen
Introducción: La determinación de las diferentes subpoblaciones de los linfocitos T en las diversas patologías y el monitoreo postratamiento ayuda a que el médico tome decisiones terapéuticas teniendo como referencia la cinética de los linfocitos $T$ localizados en sangre periférica. Métodos: Se realizó la estandarización de un perfil de moléculas de superficie para la caracterización de subpoblaciones de linfocitos T: naïve, activados y de memoria, así como las células natural killer o asesinas naturales (CD3-CD56+) en sangre periférica de individuos clínicamente sanos. Resultados: Se identificaron las subpoblaciones de linfocitos: naïve (CD3+, CD4+ o CD8+, CD45RA+, CD62L+, CCR7+), activados (CD3+, CD4+ o CD8+, CD45RA+ o CD45RO+, CD69+ y/o CRTAM+), efectores (CD3+, CD4+ o CD8+, CD45RA+, CD62L-, CCR7-), de memoria central (CD3+, CD4+ o CD8+, CD45RO+, CD62L+, CCR7+) y de memoria efectora (CD3+, CD4+ o CD8+, CD45RO+, CD62L-, CCR7-) en las poblaciones de linfocitos T CD4+ y CD8+. Se integraron los datos obtenidos con estadística descriptiva (valores mínimos, valores máximos, media, mediana). Conclusiones: Este panel será de gran utilidad para monitorear pacientes en quienes se requiera valorar el estado inmunológico desde el punto de vista celular. Particularmente, puede apoyar en el seguimiento de los pacientes en los que se requiera evaluar la reconstitución inmunológica (componente celular de estirpe T).
\end{abstract}

Palabras clave: Linfocito T. Subpoblación de linfocitos. Citometría de flujo.

\section{Detection and quantification of T-cell subpopulations and NK cells in peripheral blood from healthy individuals}

\begin{abstract}
Background: The knowledge of the participation of different subpopulations of T lymphocytes in various pathologies helps to make therapeutic decisions, having as reference the presence of the different subpopulations of the $T$ lymphocytes associated with the disease. Methods: A profile standardization of surface molecules for the characterization of subpopulations of $T$ cells was conducted: naive, activated and memory, as well as natural killer (CD3-CD56+) cells in peripheral blood of
\end{abstract}

Disponible en internet: 18-03-2019 Bol Med Hosp Infant Mex. 2019;76:66-78 www.bmhim.com 
clinically healthy individuals. Results: Naïve (CD3+, CD4+ or CD8+, CD45RA+, CD62L+, CCR7+), activated (CD3+, CD4+ or CD8+, CD45RA+ or CD45RO+, CD69+ and/or CRTAM+), effectors (CD3+, CD4+ o CD8+, CD45RA+, CD62L-, CCR7-), central memory (CD3+, CD4+ o CD8+, CD45RO+, CD62L+, CCR7+), memory effectors (CD3+, CD4+ or CD8+, CD62RO+, CD62L-, CCR7-) subpopulations were analyzed by flow cytometry. Descriptive statistics parameters were calculated (minimum values, maximum values, mean values, median). Conclusions: This panel can be very useful for monitoring patients in whom the immunological status from a cellular perspective is needed. Particularly, it can support the follow-up of patients who require an immunological reconstitution (T-cell component) evaluation.

Key words: T lymphocyte. Lymphocyte subpopulation. Flow cytometry.

\section{Introducción}

Los linfocitos T son células del sistema inmune adaptativo que maduran en el timo a partir de progenitores linfoides comunes provenientes de la médula ósea. Las subpoblaciones de linfocitos T CD4 y CD8 egresan del timo y viajan a través del sistema linfático para poblar los órganos linfoides secundarios: bazo, ganglios linfáticos ${ }^{1,2}$.

Desde hace varias décadas ha incrementado el número de moléculas que permiten identificar distintas subpoblaciones de linfocitos $T$ desde el fenotipo naïve hasta los compartimentos de memoria central y efectora, incluyendo el estado de activación y efector de los linfocitos que son detectables en sangre periférica ${ }^{3}$. A continuación, se describen las poblaciones identificadas en la periferia.

\section{Linfocitos $T$ naïve o vírgenes}

Los linfocitos maduros que egresan del timo se alojan, principalmente, en los órganos linfoides secundarios. La expresión de la isoforma CD45RA (isoforma de mayor peso molecular, puesto que conserva la expresión de los 3 exones de CD45) es uno de los principales y más antiguos marcadores para su selección. Además, la expresión de moléculas de adhesión como CD62L (que se une a E-selectina) y receptores de quimiocinas como CCR7 (se han identificado dos ligandos para este receptor, CCL19 y CCL12) conforman el fenotipo naïve. Se localizan en los órganos linfoides secundarios, donde las células presentadoras de antígeno (células dendríticas) profesionales presentan a los péptidos en el contexto de moléculas del complejo principal de histocompatibilidad $(\mathrm{CPH})$ clase I si son antígenos intracelulares, principalmente. Activan a los linfocitos T CD8 o CPH clase II (si son antígenos extracelulares, generalmente) que, a su vez, activarán a los linfocitos T CD4 ${ }^{3-6}$.

\section{Linfocitos $T$ activados}

El reconocimiento de los péptidos presentados conduce a cambios intracelulares, como liberación de las reservas de calcio, translocación de factores de transcripción al núcleo, entre otros, además de la modificación de la expresión de moléculas en la superficie. Este estado, llamado activación, se asocia con una disminución en la expresión de la isoforma CD45RA, la aparición de la molécula CD45RO (isoforma de menor peso molecular que se une a CD22, que es una proteína que se encuentra en la membrana de los linfocitos B), la disminución de CD62L y la aparición de la molécula asociada a células $T$ restringida al $\mathrm{CPH}$ de clase I, conocida como CRTAM (por sus siglas en inglés, class-I MHC-restricted T cell associated molecule) y CD69. Estas dos moléculas tienen un patrón de expresión similar: aproximadamente de 16 a 18 horas postactivación se alcanza el máximo nivel de expresión y es de carácter transitorio (es decir, las células dejan de expresar las moléculas después de cierto tiempo), por lo que se refieren como marcadores de activación temprana. La expresión de esta molécula en humanos y ratones se presenta exclusivamente en linfocitos $T$ activados $^{7-9}$. En el caso del receptor de quimiocina CCR7 (asociado con la retención de los linfocitos T en órganos linfoides), se ha reportado de baja a nula expresión en los linfocitos $T$ activados, principalmente ${ }^{10}$. Sin embargo, se ha encontrado que los linfocitos $T$ CD8+, después de una activación en modelo antígeno específico (es decir, una activación monoclonal), expresaban CCR $7^{11}$. Una de las características de la activación in vivo es que es un evento donde influye tanto el microambiente (las citocinas en el medio extracelular) como la intensidad de activación recibida (afinidad y avidez). Tal sería el caso de CCR7, ya que se pueden encontrar células antígeno específico postactivación que expresan dicha molécula.

Los linfocitos activados migran de los órganos linfoides secundarios al resto del organismo, principalmente al sitio donde se detecte la señal de daño o peligro (generalmente una zona con presencia de inflamación), además de estar presentes en sangre periférica ${ }^{12}$. Los linfocitos $T$ activados se pueden encontrar tanto en la 
población CD45RAt, que serían los recientemente activados, como en la población CD45RO+, que sería la de memoria por una reactivación.

\section{Linfocitos T efectores}

Posterior a la activación, los linfocitos $T$ adquieren funciones efectoras. En el caso de los linfocitos T CD4+, se detecta la producción de citocinas que pueden polarizar el resto de la respuesta inmunológica. Se pueden determinar poblaciones que producen principalmente interferón gamma (IFN- $\gamma$ ) y factor de necrosis tumoral alfa (TNF- $\alpha$ ) (Th1, proinflamatorias), IL-17 (Th17), IL-9 (Th9) e IL-4 e IL-10 (Th2, anti-inflamatorias).

Los linfocitos T CD8+ producen citocinas como TNF- $\alpha$ e IFN- $\gamma$ y poseen capacidad citotóxica que les permite eliminar células infectadas o tumorales a través de moléculas como granzima $B$ y perforina(11). El fenotipo de los linfocitos $T$ efectores es CD45RA+ CD62L- CCR7-. La ausencia de expresión de moléculas asociadas a la retención de las células en los órganos linfoides, CCR7 y CD62L, favorece que las células migren al sitio de inflamación para realizar sus funciones efectoras.

\section{Linfocitos T de memoria}

Si la activación de los linfocitos T naïve es apropiada, entonces se inducirá la generación de una población de memoria. Estas células se localizan principalmente en los órganos linfoides secundarios y en sangre periférica.

En el humano se utiliza la molécula CD45RO como un marcador para seleccionar la población de células que son progenie de un linfocito $T$ naïve activado a través de su receptor, receptor de células $T^{13,14}$.

La presencia o ausencia de las moléculas CCR7 y CD62L en la superficie proporcionan, en conjunto, dos fenotipos:

1) TCM (del inglés central memory $T$ cells, células $T$ de memoria central): CD45RO+ CD62L+ CCR7+

2) TEM (del inglés effector memory $T$ cells, células $T$ de memoria efectora): CD45RO+CD62L-CCR7- ${ }^{15}$

Las TCM son células que se encuentran principalmente en los órganos linfoides secundarios, y son las que mantienen el compartimento de linfocitos $T$ de memoria efectora ${ }^{16}$. En cambio, las TEM son aquellas que, ante un encuentro subsecuente con el patógeno, responden de manera inmediata con una mayor capacidad efectora (grandes cantidades de citocinas y producidas en menor tiempo) en comparación con las células efectoras provenientes de la primera diferenciación de las células naïve activadas. Estas células se encuentran principalmente circulando en el organismo ${ }^{14-17}$ debido a la ausencia de las moléculas CCR7 y CD62L.

\section{Células natural killer}

Las células natural killer (NK), también llamadas asesinas naturales, son linfocitos generados a partir de un precursor linfoide común, cuya función efectora está mediada por la producción de citocinas, especialmente altas cantidades de IFN- $\gamma$, y actividad citotóxica para eliminar células infectadas o tumorales. Se localizan en sangre periférica, en los ganglios linfáticos, piel, intestino, hígado, pulmones, útero y otros tejidos. Morfológicamente son similares a los linfocitos $\mathrm{T}$, pero sus marcadores en superficie son CD16+ CD56+ en ausencia de CD3.

Para identificar las diferentes poblaciones y subpoblaciones de linfocitos, se han desarrollado técnicas como la centrifugación en gradientes ${ }^{18}$. Sin embargo, no es posible diferenciar las células naïve o activadas simplemente por su densidad o morfología, por lo que se han utilizado métodos a través de los cuales se detectan proteínas de membrana que se utilizan como marcadores ${ }^{19}$.

El desarrollo de la tecnología de hibridomas permitió la producción de anticuerpos monoclonales capaces de reconocer epítopos únicos de las moléculas de superficie celular y, con ello, un gran avance en la identificación de fenotipos celulares, ya sea por técnicas manuales o automatizadas, además de tinciones múltiples $^{20}$. La citometría de flujo tiene gran importancia en los campos de la hematología e inmunología para el análisis completo y la caracterización detallada de las células sanguíneas ${ }^{21}$. Entre las aplicaciones clínicas más frecuentes de estos métodos se encuentran la caracterización de leucocitos en estados de inmunodeficiencia primaria o secundaria, como en el caso de infección por el virus de inmunodeficiencia adquiri$\mathrm{da}^{22,23}$ y en enfermedades oncohematológicas ${ }^{24}$. A esto se debe agregar el desarrollo de un gran número de fluorocromos, utilizados para unirse covalentemente a los anticuerpos monoclonales que se emplean en estas técnicas y así marcar múltiples moléculas para su determinación precisa en una suspensión celular heterogénea ${ }^{25,26}$.

Por lo anterior, es relevante implementar la determinación y cuantificación de las diferentes subpoblaciones de los linfocitos $\mathrm{T}$, así como conocer su asociación con el estado clínico del paciente. De esta forma, el 
médico podrá integrar los resultados, signos y síntomas para la toma de decisiones terapéuticas, considerando la presencia de las diferentes subpoblaciones de linfocitos $T$ asociados con el padecimiento.

En el presente trabajo se estandarizó un perfil de moléculas de superficie para la caracterización de subpoblaciones de linfocitos T: naïve, activados, efectores y de memoria central y efectora, además de las células NK, en sangre periférica de individuos clínicamente sanos a través de citometría de flujo.

\section{Métodos}

\section{Muestras}

Se utilizaron muestras de sangre periférica recolectadas en tubos con anticoagulante ácido etilendiaminotetraacético (EDTA) obtenidas por punción venosa de 20 individuos clínicamente sanos (ICS) de nacionalidad mexicana, quienes no cursaban con un proceso inflamatorio (por ejemplo: infecciones, neoplasias o que estuvieran bajo tratamiento farmacológico). A los participantes se les realizó un estudio médico para determinar su estado de salud, considerando los valores de una citometría hemática y química sanguínea, que proporcionan los parámetros básicos para la evaluación de la función hepática, renal y del metabolismo de los carbohidratos y lípidos.

Para el fenotipo de activación se utilizó la muestra de una paciente (8 años) con diagnóstico de infección aguda por el virus de Epstein-Barr, con una carga viral de 26,000 copias/ml en plasma determinada por reacción en cadena de la polimerasa en tiempo real.

Se realizó el conteo celular mediante una citometría hemática de cada muestra en el equipo LH 780 Beckman Coulter ${ }^{\circledR}$.

\section{Inmunofenotipo}

Para la tinción de las muestras se utilizaron tres tubos de ensayo de $12 \times 75 \mathrm{~mm}$, uno para cada panel. Se colocaron $5 \mu \mathrm{l}$ de cada anticuerpo del panel (los anticuerpos provienen de BD Biosciences ${ }^{\circledR}$, excepto el anticuerpo anti-CRTAM, de Biolegend ${ }^{\circledR}$ ) y se adicionó sangre periférica completa. Para las muestras con una

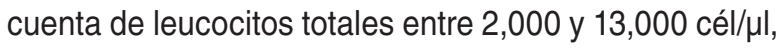
se colocaron $50 \mu \mathrm{l}$ de sangre periférica completa con EDTA para obtener una cantidad de células apropiada para el número de eventos que serán adquiridos.

La mezcla se incubó por 15 min a temperatura ambiente en oscuridad. Posteriormente, se agregaron $2 \mathrm{ml}$ de solución FACS Lysing (BD Biosciences $\left.{ }^{\circledR}\right)$ y se incubó por 10 min a temperatura ambiente en oscuridad. Al finalizar el tiempo, se centrifugaron los tubos $5 \mathrm{~min}$ a 1800 rpm, se decantaron y se lavó dos veces el botón celular con $2 \mathrm{ml}$ de FACS Flow. Al finalizar, se agregaron $350 \mu \mathrm{l}$ de FACS Flow frío (BD Biosciences ${ }^{\circledR}$ ) para obtener una suspensión celular homogénea.

La lectura de las muestras se realizó en el citómetro de flujo BD FACS Canto II siguiendo el procedimiento que marca el manual de usuario y cumpliendo los estándares de calidad establecidos en el laboratorio clínico del Hospital Infantil de México Federico Gómez para los ensayos analíticos con fines de diagnóstico. Brevemente, previo a la adquisición de las muestras, se calibró el equipo y se compensó con tinciones independientes con cada uno de los fluocromos para su correcta lectura, así como células sin teñir para ajustar la autofluorescencia. Se contabilizaron 50,000 eventos para la caracterización de las diversas poblaciones celulares.

\section{Paneles para la fenotipificación de los linfocitos $T$}

Se seleccionaron los fluorocromos considerando que no se generara ningún traslape en su lectura, aprovechando los tres rayos láser que posee el equipo. De la misma manera, se seleccionaron los anticuerpos monoclonales.

Para el anticuerpo monoclonal CRTAM, se seleccionó el fluorocromo ficoeritrina. Al ser una molécula de bajos niveles de expresión, se prefirió utilizar un fluorocromo de mayor intensidad para su detección.

Se realizaron tres paneles celulares diferentes para determinar linfocitos T naïve, activados, efectores, de memoria central y memoria efectora (Tabla 1).

Tabla 1. Panel de anticuerpos utilizados en la caracterización de las subpoblaciones de linfocitos T

\begin{tabular}{|l|c|c|c|}
\hline Fluorocromo & $\begin{array}{c}\text { Panel 1 } \\
\text { Linfocitos T naïve } \\
\text { y de memoria }\end{array}$ & $\begin{array}{c}\text { Panel 2 } \\
\text { Linfocitos T } \\
\text { activados }\end{array}$ & $\begin{array}{c}\text { Panel 3 } \\
\text { Linfocitos } \\
\text { NK }\end{array}$ \\
\hline FITC & CD45RA & CD45RA & \\
\hline PE & CRTAM & CRTAM & CD16 \\
\hline Percp- Cy 5.5 & CD45R0 & CD45R0 & \\
\hline APC & CD62L & CD69 & CD56 \\
\hline APC H7 & CD4 & CD4 & \\
\hline V450 & CD3 & CD3 & CD3 \\
\hline PE Cy7 & CCR7 & CD8 & \\
\hline
\end{tabular}




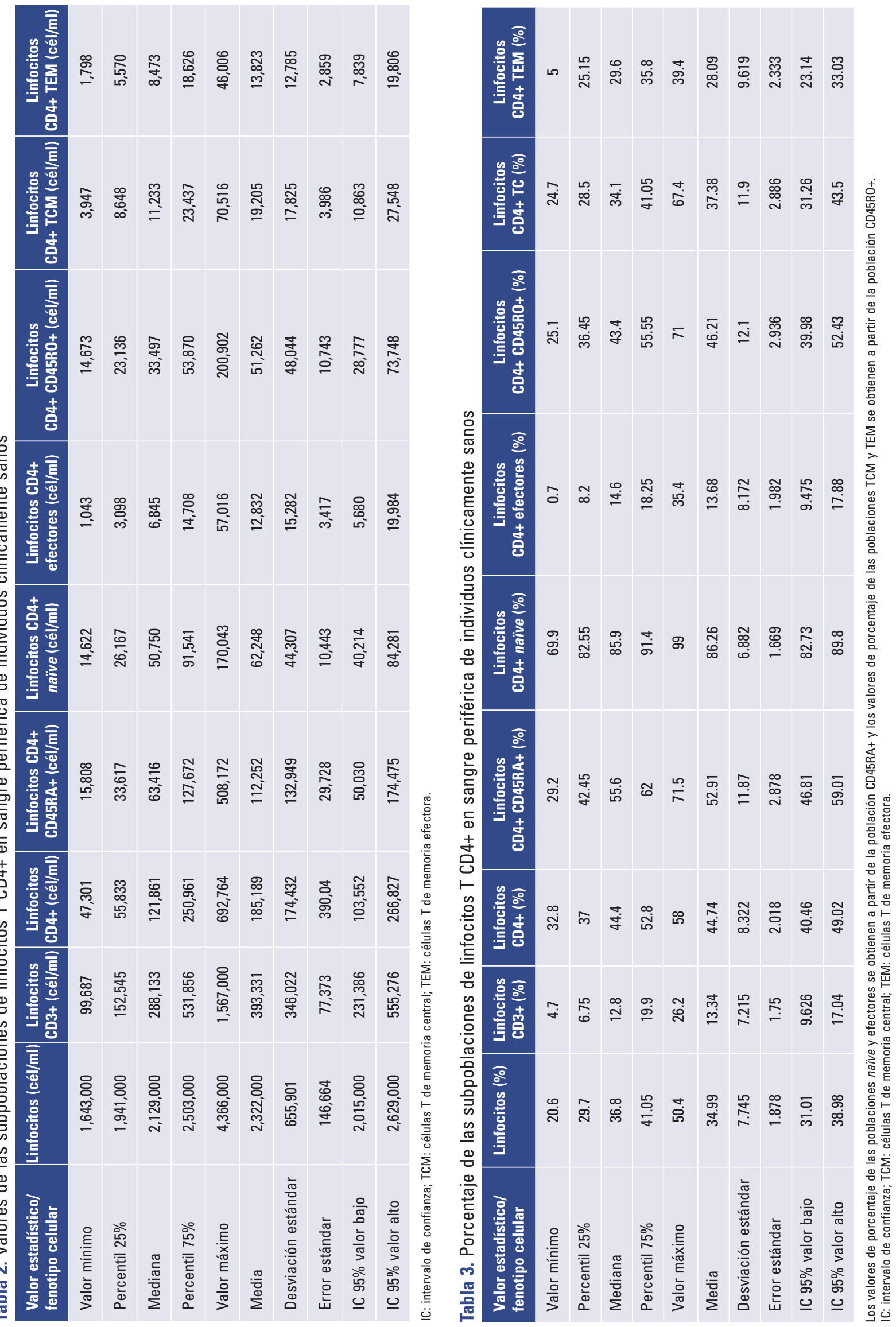



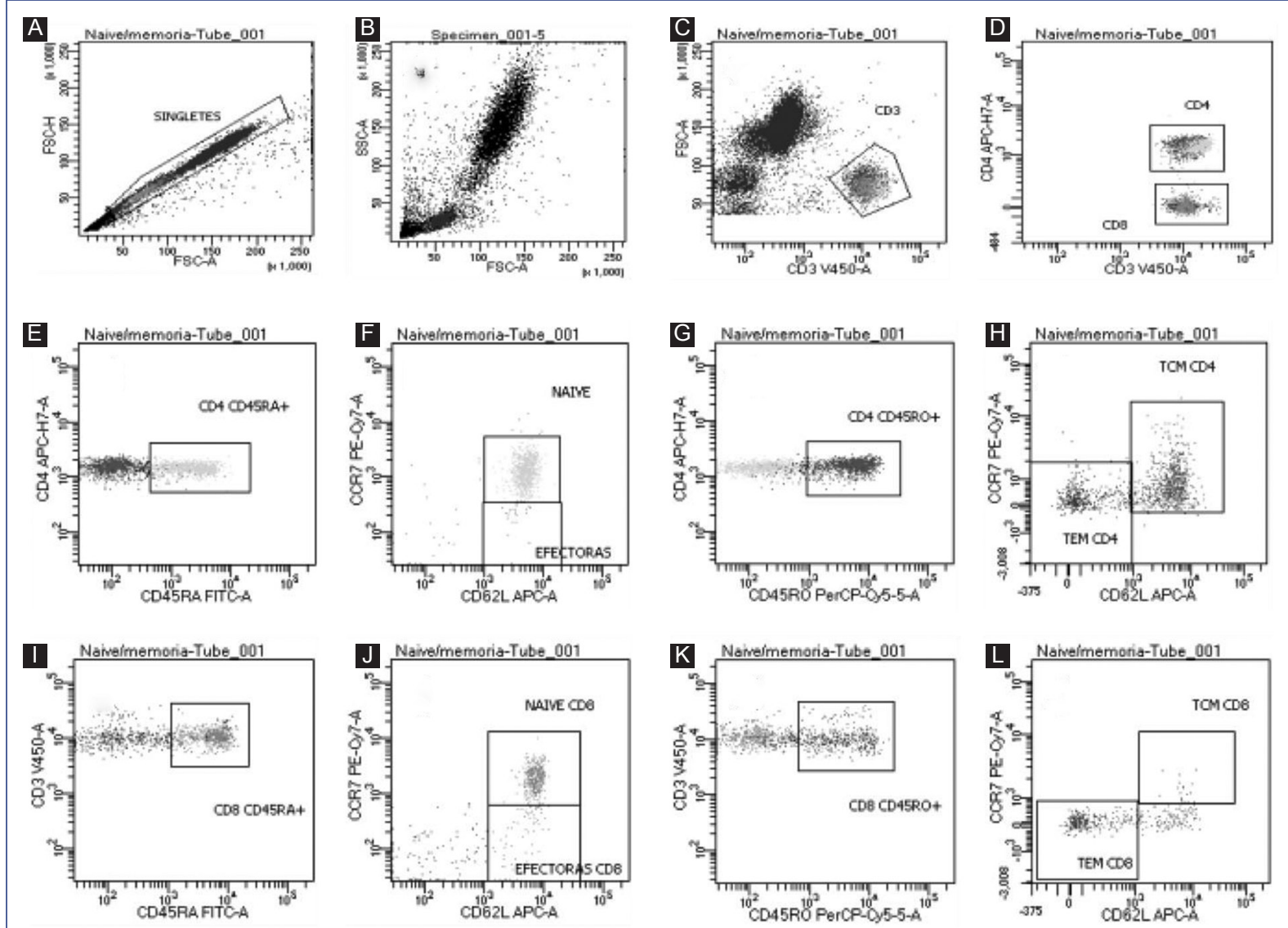

Figura 1. Fenotipificación de linfocitos T de sangre periférica. A partir de una alícuota de muestra de sangre periférica, se delimitó la población de singletes (A). Se determinaron basándose en su tamaño (FSC: dispersión frontal, por sus siglas en inglés forward scatter) y complejidad (SSC: dispersión lateral, por sus siglas en inglés side scatter) las distintas poblaciones de sangre periférica: linfocitos, monocitos y granulocitos (B). Se determinó la población CD3+ (C). A partir de esta población, se determinaron los linfocitos T CD4+ y CD8+ (D). Se analizó la expresión de las moléculas CD45RA (E) y CD45R0 (G) como marcadores de naïve y memoria, respectivamente, en la población de linfocitos CD4+ (F). De la población CD45RA (E), aquellas células que expresaran CD62L y CCR7 fueron identificadas como naïve, y aquellas CD62L- CCR7-, como efectoras (F). Mientras que el análisis de la expresión de ambas moléculas en las células CD45R0+ (G) permitió la identificación de las células de memoria central (TCM) y memoria efectora (TEM) (H). El mismo análisis se realizó para los linfocitos CD8+ (I-L). Las imágenes mostradas provienen de un individuo y son representativas del resto de participantes incluidos en el estudio.

\section{Análisis de datos}

Los resultados fueron analizados en el programa BD FACsDIVA ${ }^{\circledR}$. Se realizaron los gráficos para la identificación de cada población y una copia electrónica de respaldo, así como la plantilla del panel.

Se construyó una base de datos con la cual, mediante conversiones de los porcentajes en relación con los leucocitos totales y linfocitos obtenidos del valor proporcionado por el equipo LH 780 Beckman Coulter ${ }^{\circledR}$, se calcularon los valores absolutos (cél $/ \mathrm{ml}$ ).

En el caso de las células NK, se obtuvo el porcentaje de células CD3- CD16+ CD56+ en la población de leucocitos totales y se calculó el número absoluto de la misma manera. Para el análisis estadístico de las diferentes poblaciones celulares se utilizó el programa GraphPad Prism ${ }^{\circledR} 6.01$ para Mac OS X.

\section{Resultados}

Se analizaron 20 muestras de sangre periférica provenientes de individuos en un rango de edad de 8 a 18 años (con una media de 10 años y 6 meses y una mediana de 10 años), mestizos mexicanos, el 75\% (15) de sexo masculino. 
Tabla 4. Valores (células/ml) de las subpoblaciones de linfocitos T CD8+ en sangre periférica de individuos clínicamente sanos

\begin{tabular}{|l|c|c|c|c|c|c|c|}
\hline $\begin{array}{l}\text { Valor estadístico/ } \\
\text { fenotipo celular }\end{array}$ & $\begin{array}{c}\text { Linfocitos } \\
\text { CD8+ Cel/ } \\
\mathbf{m L}\end{array}$ & $\begin{array}{c}\text { Linfocitos } \\
\text { CD8+ CD45RA+ } \\
\text { Cel/mL }\end{array}$ & $\begin{array}{c}\text { Linfocitos } \\
\text { CD8+ naïve } \\
\text { Cel/mL }\end{array}$ & $\begin{array}{c}\text { Linfocitos } \\
\text { CD8+ efectores } \\
\text { Cel/mL }\end{array}$ & $\begin{array}{c}\text { Linfocitos } \\
\text { CD8+ CD45RO+ } \\
\text { Cel/mL }\end{array}$ & $\begin{array}{c}\text { Linfocitos } \\
\text { CD8+ TCM } \\
\text { Cel/mL }\end{array}$ & $\begin{array}{c}\text { Linfocitos } \\
\text { CD8+ TEM } \\
\text { Cel/mL }\end{array}$ \\
\hline Valor mínimo & 36186 & 23232 & 13219 & 274.1 & 12738 & 446 & 979 \\
\hline Percentil 25\% & 78397 & 41514 & 17440 & 1882 & 19731 & 719 & 11024 \\
\hline Mediana & 109396 & 68644 & 35240 & 6974 & 35035 & 1931 & 25275 \\
\hline Percentil 75\% & 196850 & 154529 & 63307 & 11171 & 53473 & 4201 & 38052 \\
\hline Valor máximo & 542299 & 380694 & 148283 & 33882 & 157267 & 14592 & 125656 \\
\hline Media & 155947 & 110535 & 51990 & 9625 & 43701 & 3218 & 30863 \\
\hline Desviación estándar & 126536 & 102996 & 45445 & 9910 & 33907 & 3607 & 29568 \\
\hline Error estándar & 28294 & 23031 & 10712 & 2216 & 7582 & 806.4 & 6612 \\
\hline IC 95\% valor bajo & 96725 & 62331 & 29390 & 4987 & 27832 & 1530 \\
\hline IC 95\% valor alto & 215168 & 158739 & 74589 & 14262 & 59570 & 4906 \\
\hline
\end{tabular}

IC: intervalo de confianza; TCM: células T de memoria central; TEM: células T de memoria efectora.

A partir de la delimitación de los eventos sencillos (Fig. 1A) se consideraron las características de tamaño y complejidad para seleccionar las células vivas (Fig. 1B). Posteriormente, se definió la población de linfocitos $\mathrm{T}$ basándose en la expresión de la molécula CD3 (Fig. 1C); a partir de esta, se realizó la compartamentalización de células CD4+ y CD8+ (Fig. 1D). La mediana del porcentaje de linfocitos T CD3+ fue del $20 \%$, inferior a lo reportado en población pediátrica ${ }^{27}$. En esta región, las poblaciones CD4+ y CD8+ fueron del $55.3 \%$ y $47.5 \%$, respectivamente, y se obtuvo una relación CD4:CD8 de 1.24, similar a lo reportado anteriormente ${ }^{25}$.

Se analizaron los diferentes perfiles celulares en las poblaciones de linfocitos T CD4+ y CD8+, esto es linfocitos naïve, efectores, memoria central y memoria efectora (Figs. 1E-L). Utilizando un perfil de expresión de CD45RA+ CCR7+ CD62L+, se determinó la frecuencia y el número absoluto de linfocitos $T$ naïve y los valores de la mediana obtenidos de 92.60 y 67.80 para los linfocitos T CD4+ y CD8+, respectivamente (Tablas 2 a 5). Los valores de porcentaje de las poblaciones naïve y efectores se obtuvieron a partir de la población CD45RAt.

Utilizando el mismo panel de tinción, es posible definir las células efectoras CD45RA+ CCR7- CD62L- en cada una de las subpoblaciones. Se calculó un porcentaje de 14.6 y 8.8 de la población de linfocitos T CD4+ y CD8+ que expresan CD45RA+, respectivamente (Tablas 3 y 5 ).
El fenotipo de linfocitos $T$ activados se definió como aquellas células que expresaran CD69, un marcador de activación temprana, y CRTAM, una molécula recientemente descrita y asociada con el estado de activación. La determinación de este fenotipo se realizó tanto en las poblaciones CD45RA+ como CD45RO+, con la finalidad de calcular las células naïve (CD45RA+) activadas recientemente y las activadas/memoria (CD45RO+) posterior a su reactivación. El análisis de las células con fenotipo de activación mostró que en las poblaciones de linfocitos T CD4+ y CD8+ existe una población discreta de células CD45RA+ y CD45RO+ que expresan CD69 y escasas células CRTAM+ (Fig. 2). Cabe destacar que no se detectaron células que mostraran coexpresión de CD69 y CRTAM (Fig. 2 y Tabla 6).

Considerando que las muestras provenían de individuos clínicamente sanos, se analizó además una muestra de un paciente que cursaba con una infección aguda por el virus de Epstein-Barr (VEB). Se observó que, en la población de linfocitos T CD4+, en el compartimento CD45RA+, existía un aumento de 2.85 veces de células CD69+ (Figs. 2A y 2E), mientras que en la población $\mathrm{CD} 45 \mathrm{RO}+$, este aumento fue de 2.1 veces (Figs. 2B y 2F), comparado con lo observado en los ICS. Por otro lado, en las células CRTAM+ se observó un incremento muy importante, de aproximadamente 8.9 veces, en las células CD45RA+ (Figs. $2 A$ y $2 E$ ) y de 7.6 veces en la población CD45RO+ (Figs. 2B y 2F) con respecto a lo observado en los ICS, mostrando una diferencia importante en presencia de un estímulo 
antigénico que induce la activación de las células $T$, en este caso, el VEB.

Para el caso de las células CD8+, se observó un incremento en aquellas que expresaban CD69, tanto en la población CD45RA+ (Figs. $2 \mathrm{C}$ y $2 \mathrm{G}$ ) como en CD45RO+ (Figs. 2D y 2H): 2.1 y 1.4 veces, respectivamente. El análisis de la expresión de CRTAM mostró un incremento de 5.6 y 9.1 veces en las poblaciones CD45RA+ (Figs. 2C y 2G) y CD45RO+ (Figs. 2D y 2H), respectivamente. Es destacable que tampoco se detectaron células que expresaran ambos marcadores, CD69 y CRTAM, en esta muestra. El análisis de la expresión de CD69 y CRTAM mostró un incremento de 13.8 y 10.4 veces en las poblaciones CD45RA+ (Figs. $2 \mathrm{C}$ y $2 \mathrm{G}$ ) y CD45RO+ (Figs. 2D y 2H), respectivamente.

El análisis de la población de memoria, utilizando la expresión de moléculas CD45RO, CCR7 y CD62L, permitió definir las subpoblaciones TCM y TEM para los compartimentos de células CD4+ y CD8+. El análisis mostró que la población TCM (CD45RO+ CD62L+ CCR7+) y TEM (CD45RO+ CD62L- CCR7-) estaba representada por una mediana de 34.1 y 29.6 en la población de células CD4+ (Tabla 3), mientras que para los CD8+, la mediana de las células TCM fue de $4 \%$, y para las TEM, de $77.5 \%$ (Tabla 5). Los valores de porcentaje de las poblaciones TCM y TEM se obtuvieron a partir de la población CD45RO+.

La determinación y cuantificación de las células NK (CD16+ CD56+) (Figs. 3A y B) mostró una media de $29.67 \%$, con una mediana de $28 \%$ (IC 95\%: 22-37.26\%) en los leucocitos de sangre periférica (Tabla 7). Los valores obtenidos de las células NK son superiores en el valor de la media en comparación con lo reportado en estudios realizados en Holanda (media de 14\%; IC 95\%: $4-51 \%$ ) $^{27}$ y en China (media de $18 \%$; IC 95\%: $10.12-28.34 \%)^{28-30}$.

\section{Discusión}

Caracterizar y cuantificar las diferentes subpoblaciones de linfocitos $T$ en sangre periférica permitió conocer la distribución (números absolutos y porcentaje) en individuos clínicamente sanos. Al analizar la población de linfocitos T CD3+, se observó que el uso de CD45RA delimita a las células naïve bona fide dentro del compartimento de células CD4+. Sin embargo, para los CD8+, es necesario el uso de marcadores adicionales, como CD62L y CCR7, si se desea identificar a la población naïve de manera precisa. Esto es una diferencia importante a considerar cuando el interés de la cuantificación de las células naïve es determinante en el seguimiento clínico del paciente, como puede ser el monitoreo de receptores de células progenitoras hematopoyéticas.

La diferencia en los porcentajes obtenidos en el presente trabajo en comparación con otros radica principalmente en que las subpoblaciones fueron calculadas en la población parental, es decir, CD45RA+ CD4+ 0 CD8+ naïve, activados, efectores y CD45RO+ CD4+ 0 CD8+ TCM y TEM, y el valor absoluto calculado basándose en los leucocitos totales.

La presencia de células activadas es escasa en ambos compartimentos, tanto CD45RA como CD45RO para las poblaciones CD4+ y CD8+. Esto era esperado, pues los participantes no presentaban signos ni síntomas asociados a procesos infecciosos agudos. Esta observación es congruente con la presencia discreta de la población de células efectoras. La detección de estas células en ICS se debe al contacto continuo con microorganismos (aun en ausencia de signos y síntomas clínicos que sugieran un proceso infeccioso agudo), que induce la respuesta inmunitaria adaptativa y, después de limitar la infección a través de sus funciones efectoras, su eliminación mediante apoptosis. Cabe destacar que la frecuencia de células efectoras es mayor en la población CD8+ que en las células CD4+.

El análisis de las poblaciones de memoria TCM y TEM en las células CD4+ mostró un mayor porcentaje de las primeras. Para el caso de las células CD8+, se observa un mayor porcentaje de TEM comparado con las TCM. En la población de células CD4+, la presencia de una mayor subpoblación de TCM permitiría tener una reserva de precursores de TEM que cooperaría con los linfocitos B para generación de anticuerpos y el desempeño de su capacidad efectora per se. En las células CD8+, la población de células TEM se encuentran en mayor número, lo cual permite una actuación pronta y eficiente (grandes cantidades de citocinas y producidas en menor tiempo) ante infecciones intracelulares, comparada con las generadas a partir de las células naïve activadas. Es importante enfatizar que las poblaciones naïve y de memoria sufren modificaciones a lo largo de la vida, pues la generación de linfocitos $T$ naive se encuentra reducida al depender del timo, un órgano que involuciona, por lo que disminuye el número de linfocitos $T$ naïve en periferia ${ }^{5,31}$. La población de células de memoria sufre modificaciones durante los encuentros con diferentes patógenos, lo que modifica el repertorio y las subpoblaciones TCM y TEM del mismo compartimento.

Es importante establecer un sistema de análisis que comprenda la elección de las moléculas que definirán las poblaciones de interés, así como la determinación 

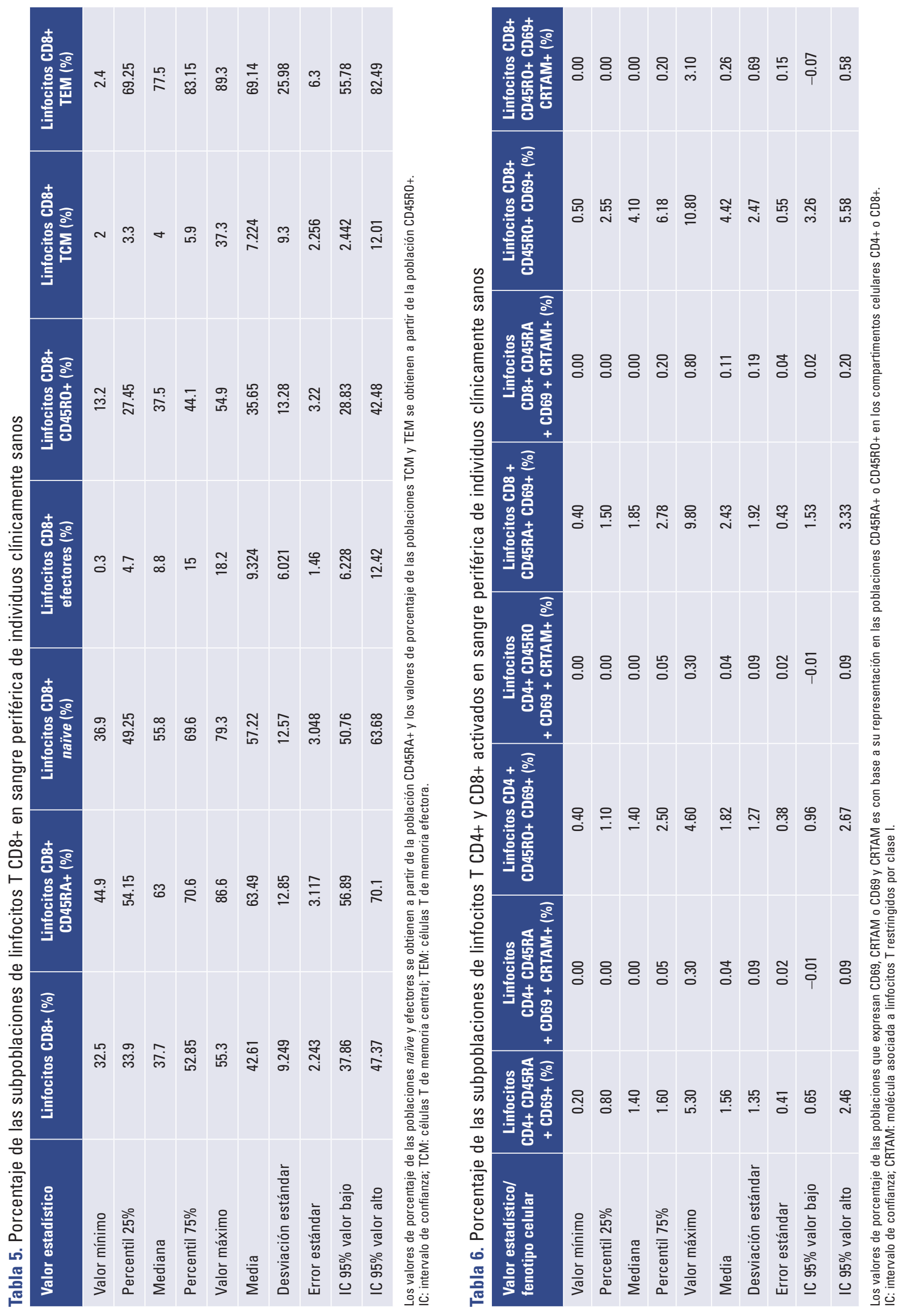


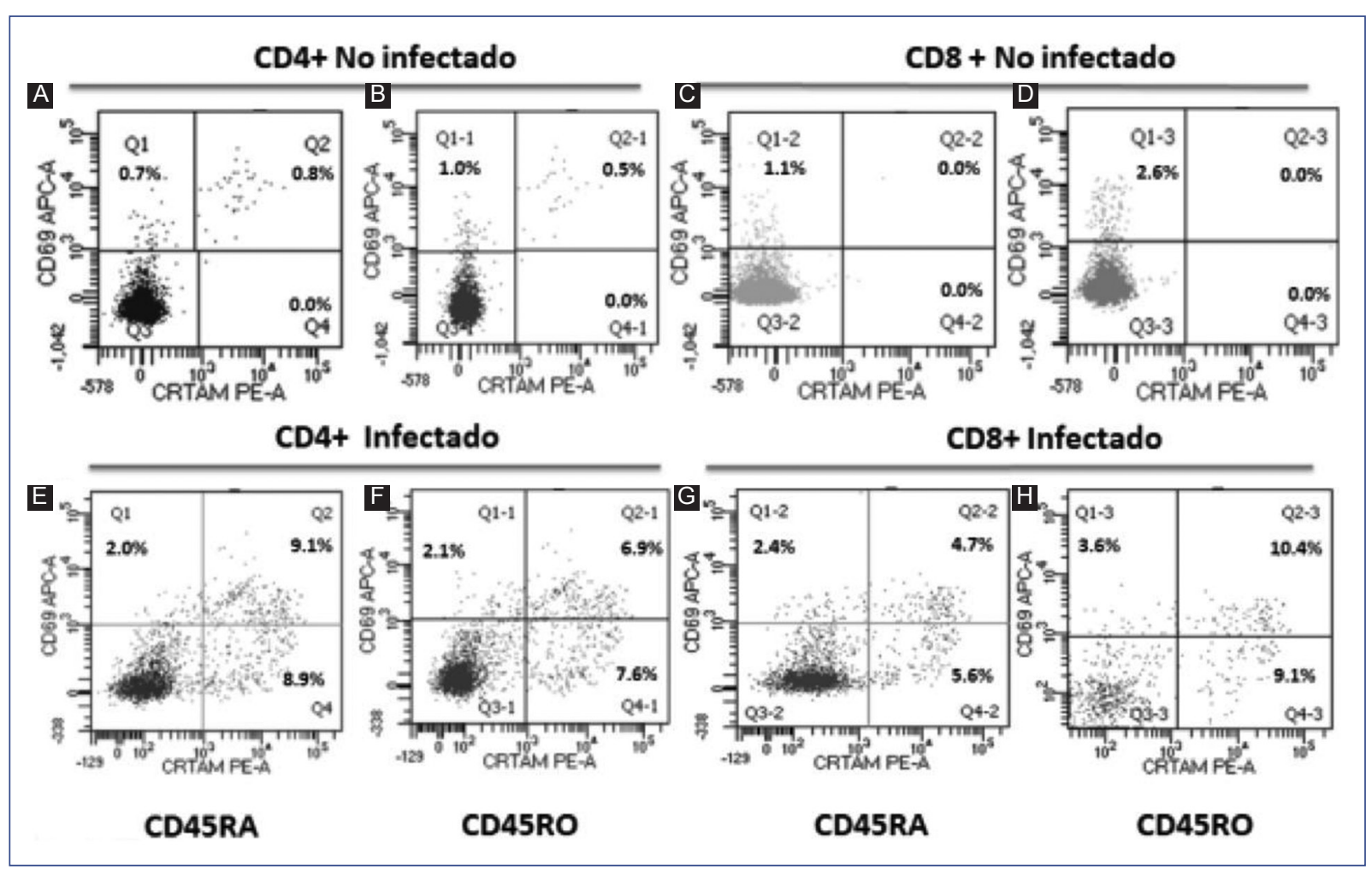

Figura 2. Fenotipificación de la población de linfocitos T activados. A partir de las poblaciones CD4+ (A y E) y CD8+ (C y G) que expresaban la molécula CD45RA (naïve), se analizó la expresión de CD69 y CRTAM (marcadores tempranos de activación). Se realizó el mismo análisis en las poblaciones $C D 4+C D 45 R 0+(\mathbf{B}$ y F) y CD8+ CD45RO+ (D y H) en una muestra representativa del grupo de individuos clínicamente sanos (fila superior) y un individuo infectado con el virus Epstein Barr (fila inferior).

de porcentajes (relativa a la población de linfocitos o leucocitos totales) en cada laboratorio donde se utilizarán como parámetros para el monitoreo o determinación única en muestras de sangre periférica. Esto debido a que los diferentes protocolos utilizados para la caracterización de poblaciones celulares deben describirse de tal manera que puedan ser reproducidos y no sobre-estimados, como el uso único de CD45RA para definir la población naïve. En este aspecto, se han descrito variaciones significativas entre usuarios, equipos y métodos de tinción y cálculo de porcentajes y números absolutos, lo cual debe ser un punto crucial cuando se presenta información de número y frecuencia en los diversos grupos celulares ${ }^{32,33}$.

Dado que esta relación se ve disminuida, debido al aumento de la cantidad de linfocitos T CD8+ que actúan como células efectoras del sistema inmunológico al eliminar células tumorales o potencialmente infectadas por virus, bacterias o protozoarios ${ }^{34}$, es congruente con el estado de los participantes (ICS).

Asimismo, se determinó la presencia de células con un fenotipo de activación, tanto en la subpoblación
CD45RA+ como en CD45RO+, considerando que las moléculas de superficie CD69 y CRTAM son marcadores tempranos que pudieran expresarse tanto en las células activadas por primera vez, es decir las células naive (CD45RA+), y aquellas de memoria (CD45RO+) generadas a partir de la activación de linfocitos $T$ naïve que respondieron a algún estímulo, como podría ser el caso de infecciones virales ${ }^{35}$ o bacterianas, o bien, por el reconocimiento de un aloantígeno ${ }^{36}$. Se observó que la presencia de células con dichas características (CD69+CRTAM-, CD69+ CRTAM+ y CD69-CRTAM+) es casi nula en individuos clínicamente sanos, tanto en el compartimento de linfocitos T CD4+ como CD8+, en tanto que se encontraron enriquecidas en un individuo que cursaba con una infección viral aguda. La expresión transitoria de CD69 es un marcador clásico de activación temprana y, aunque CRTAM comparte dichas características, se desconocía la expresión en condiciones de infección in vivo. La relevancia de incluir un segundo marcador de activación, además de CD69, permite tener un cálculo preciso de la población de linfocitos $T$ activados debido a que la expresión 


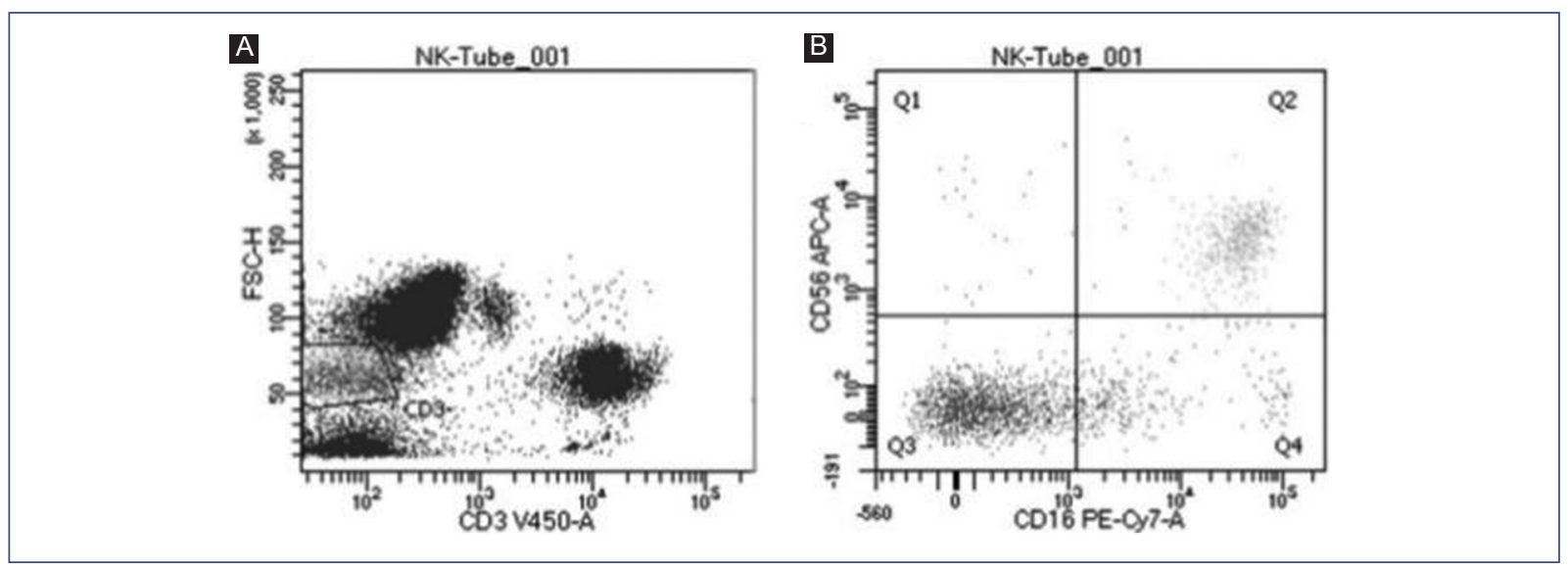

Figura 3. Identificación de las células natural killer en sangre periférica. A partir de la región de células vivas y morfología de linfocitos (tamaño pequeño y poco granular), se realizó la identificación de la población CD3- (A). De esta población, se analizó la expresión en la superficie de las moléculas CD16 y CD56 para la identificación de las células NK: CD16+ CD56+ (B). Esta es una muestra representativa del grupo de individuos clínicamente sanos.

Tabla 7. Valores de las células NK en sangre periférica de individuos clínicamente sanos

\begin{tabular}{|l|c|c|}
\hline Valor estadístico & Células NK (cél/ml) & Células NK (\%) \\
\hline Valor mínimo & 18,284 & 10.5 \\
\hline Percentil 25\% & 28,313 & 18.8 \\
\hline Mediana & 58,177 & 28 \\
\hline Percentil 75\% & 87,420 & 40.8 \\
\hline Valor máximo & 130,597 & 51.1 \\
\hline Media & 60,530 & 29.67 \\
\hline Desviación estándar & 33,430 & 12.55 \\
\hline Error estándar & 9,272 & 3.482 \\
\hline IC 95\% valor bajo & 40,328 & 22.08 \\
\hline IC 95\% valor alto & 80,732 & 37.26 \\
\hline
\end{tabular}

IC: intervalo de confianza; NK: células asesinas naturales (natural killer).

heterogénea de ambas moléculas permite distinguir tres fenotipos de activación: CD69+ CRTAM-, CD69+ CRTAM+ y CD69-CRTAM+. Se desconoce si pertenecen a subpoblaciones independientes generadas durante la activación, o bien, siguen una línea de diferenciación. Sería importante conocer el impacto de cada una en la respuesta efectora (producción de citocinas y capacidad citotóxica) ante una infección viral, por ejemplo, de cada subpoblación identificada.

El uso de un panel de anticuerpos que permitan distinguir esta población es de utilidad, específicamente en aquellos casos en los cuales una expansión clonal asociada con un estado de infección o de rechazo de trasplante (sólido o de células progenitoras hematopoyéticas) pudiera confundirse con una reconstitución del compartimento de células $T$.

La obtención de información a partir de la fenotipificación de los linfocitos $T$ debe considerarse como un dato adicional provisto por el laboratorio clínico, que debe ser integrado a las características clínicas del paciente, tratamiento, detección de infecciones virales o bacterianas, entre otros. Su demanda debe ser valorada en aquellas situaciones en las que se requiere conocer el perfil (fenotipo y número absoluto) de las subpoblaciones naïve, activado, efector o de memoria en los compartimentos de linfocitos T CD4+ o CD8+. Esto resulta muy útil, por ejemplo, en individuos sometidos a trasplante de células progenitoras hematopoyéticas que requieren ser monitoreados para establecer el éxito del tratamiento, así como en individuos en los que la identificación de ciertas subpoblaciones podría apoyar en la identificación de deficiencias en las subpoblaciones de linfocitos $T$ asociados con la presencia de infecciones recurrentes o baja respuesta inmunitaria protectora después de una vacunación.

Se debe considerar que las poblaciones y subpoblaciones celulares en el compartimento de linfocitos $T$ se encuentran en homeostasis dinámica, dependiendo del número de eventos antigénicos al que haya sido expuesto el individuo de manera conocida: vacunación, contagio de infecciones conocidas o determinadas 0 de agentes desconocidos por los que se haya generado una respuesta inmunológica, además de la 
edad $^{37}$, por lo que los datos de las subpoblaciones de linfocitos $T$ deben interpretarse de manera individual y considerar que la referencia para las subpoblaciones de linfocitos $T$ debe ser el mismo individuo, antes o después de una intervención clínica o terapéutica. De esta manera, se podría contrarrestar la heterogeneidad observada en las subpoblaciones entre individuos.

En el caso de las células NK, se observaron valores similares a los reportados ${ }^{38}$ y la definición de la población CD3- CD16+ CD56+ fue claramente delimitada, por lo que también podría ser utilizada como un dato adicional en la caracterización del perfil de células con capacidad citotóxica.

Con la estandarización de un panel para la caracterización de subpoblaciones de linfocitos $T$ naïve, activados, efectores y de memoria en sangre periférica, y el conocimiento de la distribución de este grupo de células en ICS, se demostró que esta herramienta es útil y capaz de marcar diferencias en una subpoblación de células activadas y efectoras, en presencia y ausencia de un estímulo antigénico (en este caso, una infección viral). Es necesario continuar con la inclusión de una muestra mayor y homogénea para conocer los valores de cada una de las subpoblaciones y detectar alguna alteración que merezca un análisis detallado, o bien, darles seguimiento a los individuos en los que el uso de este panel puede detectar variaciones que sirvan de herramienta para que el equipo clínico tome decisiones terapéuticas, e incluso sirvan de monitoreo de su avance y eficacia del tratamiento.

Como conclusiones, se logró estandarizar un panel para la caracterización de subpoblaciones de linfocitos T naïve, activados, efectores y de memoria, así como de las células NK en sangre periférica, utilizando citometría de flujo (citómetro BD FACS CANTO $\|^{\circledR}$ de ocho colores). Este panel será de gran utilidad para dar seguimiento a pacientes que requieran de valoraciones frecuentes de su estado inmunológico desde el punto de vista celular, y a los pacientes de los cuales se requiera evaluar la reconstitución inmunológica, particularmente el linaje T.

\section{Responsabilidades éticas}

Protección de personas y animales. Los autores declaran que para esta investigación no se han realizado experimentos en seres humanos ni en animales.

Confidencialidad de los datos. Los autores declaran que han seguido los protocolos de su centro de trabajo sobre la publicación de datos de pacientes.
Derecho a la privacidad y consentimiento informado. Los autores declaran que en este artículo no aparecen datos personales de pacientes. Los participantes fueron informados de las características del protocolo, así como el riesgo mínimo al que serían sometidos para la obtención de la muestra. Los autores han obtenido el consentimiento informado de los pacientes o sujetos referidos en el artículo. Este documento obra en poder del autor de correspondencia.

\section{Conflicto de intereses}

Los autores declaran no tener ningún conflicto de interés.

\section{Financiamiento}

El presente estudio fue aprobado por el Comité de Ética e Investigación del Hospital Infantil de México Federico Gómez considerando los documentos internacionales, como la Declaración de Helsinki e Informe Belmont, y nacionales, como la Ley General de Salud y la NOM-012-SSA3-2012. Este protocolo forma parte del proyecto $\mathrm{HIM} / 2017 / 038$.

\section{Bibliografía}

1. Goldsby K. Inmunología. México: McGraw Hill; 2004

2. Abbas AK, Lichman AH PS. Immunología celular y molecular. Barcelona: Elsevier Saunders; 2015

3. Appay V, Sauce D. Naive T cells: the crux of cellular immune aging? Exp Gerontol. 2014;54:90-3.

4. Taub DD, Longo DL. Insights into thymic aging and regeneration. Immunol Rev. 2005;205:72-93.

5. Linton PJ, Dorshkind K. Age-related changes in lymphocyte development and function. Nat Immunol. 2004:5:133-9.

6. Qi Q, Zhang DW, Weyand CM, Goronzy JJ. Mechanisms shaping the naïve $T$ cell repertoire in the elderly-thymic involution or peripheral homeostatic proliferation? Exp Gerontol. 2014:54:71-4

7. Medina-Contreras O, Soldevila G, Patiño-Lopez G, Canche-Pool E, Valle-Rios R, Ortiz-Navarrete V. Role of CRTAM during mouse early T lymphocytes development. Dev Comp Immunol. 2010;34:196-202.

8. Wong SH, Vannberg FO, Spencer AJ, van der Weyden L, Hill AVS, Wyllie DH. CRTAM confers late-stage activation of CD8+ T cells to regulate retention within lymph node. J Immunol. 2010;184:4052-3.

9. Beristain-Covarrubias N, Canche-Pool EB, Ramirez-Velazquez C, Barragan-Galvez JC, Gomez-Diaz RA, Ortiz-Navarrete V. Class I-restricted T cell-associated molecule is a marker for IFN- $\gamma$-producing iNKT cells in healthy subjects and patients with type 1 diabetes. J Interferon Cytokine Res. 2017;37:39-49.

10. Calabresi PA, Allie R, Mullen KM, Yun SH, Georgantas RW, Whartenby KA. Kinetics of CCR7 expression differ between primary activation and effector memory states of $\mathrm{T}(\mathrm{H}) 1$ and $\mathrm{T}(\mathrm{H}) 2$ cells. J Neuroimmunol. 2003;139:58-65.

11. van Leeuwen EMM, van Buul JD, Remmerswaal EBM, Hordijk PL, ten Berge IJM, van Lier RAW. Functional re-expression of CCR7 on CMV-specific CD8+ T cells upon antigenic stimulation. Int Immunol. 2005;17:713-9.

12. Krammer PH, Arnold R, Lavrik IN. Life and death in peripheral T cells. Nat Rev Immunol. 2007;7:532-42.

13. Mahnke YD, Brodie TM, Sallusto F, Roederer M, Lugli E. The who's who of T-cell differentiation: Human memory T-cell subsets. Eur J Immunol. 2013;43:2797-809.

14. Weninger $W$, Manjunath $\mathrm{N}$, von Andrian $\mathrm{UH}$. Migration and differentiation of CD8+ T cells. Immunol Rev. 2002;186:221-33.

15. Lanzavecchia A, Sallusto F. Understanding the generation and function of memory T cell subsets. Curr Opin Immunol. 2005;17:326-32. 
16. Zanetti M, Franchini G. T cell memory and protective immunity by vaccination: is more better? Trends Immunol. 2006;27:511-7.

17. Sallusto F, Lenig D, Förster R, Lipp M, Lanzavecchia A. Two subsets of memory $\mathrm{T}$ lymphocytes with distinct homing potentials and effector functions. Nature. 1999;401:708-12.

18. Bøyum A. Isolation of lymphocytes, granulocytes and macrophages. Scand J Immunol. 1976; Suppl 5:9-15.

19. Brain P, Gordon J, Willetts WA. Rosette formation by peripheral lymphocytes. Clin Exp Immunol. 1970;6:681-8.

20. Bonner WA, Hulett HR, Sweet RG, Herzenberg LA. Fluorescence activated cell sorting. Rev Sci Instrum. 1972;43:404-9.

21. Appay V, van Lier RAW, Sallusto F, Roederer M. Phenotype and function of human T lymphocyte subsets: consensus and issues. Cytometry $A$. 2008;73:975-83.

22. Corneau A, Cosma A, Even S, Katlama C, Le Grand R, Frachet V, et al. Comprehensive mass cytometry analysis of cell cycle, activation, and coinhibitory receptors expression in CD4 T cells from healthy and HIV-infected individuals. Cytom Part B Clin Cytom. 2017;92:21-32.

23. Siegel RL, Fox RW. A longitudinal study of a patient with acquired immunodeficiency syndrome using $\mathrm{T}$ cell subset analysis. Adv Exp Med Biol. 1983;166:295-303.

24. Toubert A, Clave E, Talvensaari K, Douay C, Charron D. New tools in assessing immune reconstitution after hematopoietic stem cell transplantation. Vox Sang. 2000;78:29-31.

25. Santagostino A, Garbaccio G, Pistorio A, Bolis V, Camisasca G, Pagliaro P, et al. An Italian national multicenter study for the definition of reference ranges for normal values of peripheral blood lymphocyte subsets in healthy adults. Haematologica. 1999;84:499-504.

26. Flores MGP, Vázquez MIC, Camaño MEV, Bayardo RLG, Contreras FO, Galicia Tapia J, et al. Determinación de concentraciones de subpoblaciones de linfocitos en donadores adultos sanos del CMN 20 de Noviembre, ISSSTE. Rev Espec Médico-Quirúrgicas. 2013; 18:228-34.
27. Schatorié EJH, Gemen EFA, Driessen GJA, Leuvenink J, van Hout RWNM, de Vries E. Paediatric reference values for the peripheral T cell compartment. Scand J Immunol. 2012;75:436-44.

28. Jiang $Y$, Zhang $L$, Wen $D$, Ding $Y$. Role of physical and chemical interactions in the antibacterial behavior of $\mathrm{ZnO}$ nanoparticles against $E$. coli. Mater Sci Eng C Mater Biol Appl. 2016;69:1361-6.

29. Lin C, Shao B, Zhou Y, Niu X, Lin Y. Maternal high-fat diet influences stroke outcome in adult rat offspring. J Mol Endocrinol. 2016;56:101-12.

30. Ding Y, Zhou L, Xia Y, Wang W, Wang Y, Li L, et al. Reference values for peripheral blood lymphocyte subsets of healthy children in China. J Allergy Clin Immunol. 2018;142:970-3.

31. Jiao Y, Qiu Z, Xie J, Li D, Li T. Reference ranges and age-related changes of peripheral blood lymphocyte subsets in Chinese healthy adults. Sci China Ser C Life Sci. 2009;52:643-50.

32. Rivadeneyra-Espínoza L, Pérez-Romano B, González-Flores A, Guzmán-García MO, Carvajal-Armora F, Ruiz-Argüelles A. Instrument- and protocol-dependent variation in the enumeration of CD34+ cells by flow cytometry. Transfusion. 2006;46:530-6.

33. Ruiz-Argüelles A, Pérez-Romano B. Immunophenotypic analysis of peripheral blood lymphocytes. Curr Protoc Cytom. 2000;11:6.5.1-14.

34. Ahmed R, Gray D. Immunological memory and protective immunity: understanding their relation. Science. 1996;272:54-60.

35. Griffiths SJ, Riddell NE, Masters J, Libri V, Henson SM, Wertheimer A, et al. Age-associated increase of low-avidity cytomegalovirus-specific CD8+ T cells that re-express CD45RA. J Immunol. 2013;190:5363-72.

36. Akbar AN, Salmon M, Ivory K, Taki S, Pilling D, Janossy G. Human CD4+CD45R0+ and CD4+CD45RA+ T cells synergize in response to alloantigens. Eur J Immunol. 1991:21:2517-22.

37. Clement LT. Isoforms of the CD45 common leukocyte antigen family: markers for human T-cell differentiation. J Clin Immunol. 1992;12:1-10.

38. Bisset LR, Lung TL, Kaelin M, Ludwig E, Dubs RW. Reference values for peripheral blood lymphocyte phenotypes applicable to the healthy adult population in Switzerland. Eur J Haematol. 2004;72:203-12. 